\title{
Case Report Size of Metastatic Lymph Nodes
}

\author{
L. Uriev, ${ }^{1}$ I. Maslovsky, ${ }^{2}$ F. Barak, ${ }^{3}$ and D. Ben-Dor \\ ${ }^{1}$ Institute of Pathology, Barzilai Medical Centre, 7830604 Ashkelon, Israel \\ ${ }^{2}$ Tel Hai Clinic, 7751056 Ashdod, Israel \\ ${ }^{3}$ Institute of Oncology, Barzilai Medical Centre, 7830604 Ashkelon, Israel \\ Correspondence should be addressed to I. Maslovsky; igorgn@012.net.il
}

Received 2 March 2013; Accepted 28 March 2013

Academic Editors: P. Kornprat, A. Mima, Z. Schaff, and A. N. Walker

Copyright (c) 2013 L. Uriev et al. This is an open access article distributed under the Creative Commons Attribution License, which permits unrestricted use, distribution, and reproduction in any medium, provided the original work is properly cited.

We present a case and review of the literature of well-differentiated sigmoid adenocarcinoma with numerous metastases into pericolic lymph nodes. All positive lymph nodes were small. The authors concluded that there is no clear correlation between nodal size and the likelihood of metastasis in the lymph node, and the status of small lymph nodes must receive special attention by clinicians and pathologists.

\section{Case Report}

A 64-year-old man presented with rectal bleeding and anemia. Colonoscopy revealed polypoid tumor in sigmoid colon. The biopsy showed well-differentiated adenocarcinoma. Abdominal computerized tomography demonstrated neither regional nor distant metastasis. Anterior rectosigmoid resection was performed. The postoperative course was unremarkable.

\section{Pathological Findings}

Large bowel fragment $12 \mathrm{~cm}$ in length showed a $4 \mathrm{~cm}$ polypoid tumor of sigmoid colon. Microscopic examination revealed well-differentiated adenocarcinoma arising in preexisting tubulovillous adenoma and invading into submucosa with foci of vascular invasion. Metastases were found in 12 of 13 pericolic lymph nodes. Diameter of metastatic nodes was from $1.5 \mathrm{~mm}$ up to $5 \mathrm{~mm}$ with partial to subtotal replacement of lymph node parenchyma and focal extracapsular extension. There were 8 involved lymph nodes from $1.5 \mathrm{~mm}$ to $2.9 \mathrm{~mm}$ in diameter. And 4 metastatic nodes had diameter from $3.0 \mathrm{~mm}$ to $5 \mathrm{~mm}$. The mean size of involved lymph nodes was $2.9 \mathrm{~mm}$ (Figures 1 (a) and 1(b)).

\section{Discussion and Review}

The standard assessment of nodal status requires a histological examination of the lymph nodes recovered from the mesocolic or perirectal tissues. The number of involved lymph nodes is a relevant prognostic parameter which determines the duration of survival in patients with colonic carcinoma. Does the nodal size reflect the likelihood of metastasis in the lymph node? The general point of view is that there is positive correlation between the above. But in our case all involved nodes were small (most of them were less or equal to $2.9 \mathrm{~mm}$ ) and were not found at computerized tomography examination of abdominal cavity before the operation. Different opinions are present in the literature.

So, Cserni concluded that metastatic lymph nodes are significantly larger than uninvolved ones. Positive nodes tend to be larger, but reactive ones may also be large. The size has much to do with the detectability of a lymph node; large nodes are easier to recover [1].

Kotanagi et al. found only a nonsignificant trend for positive nodes to be larger than negative ones [2].

In contrast, Mönig et al. reported that metastatic nodes were on the whole larger [3]. 


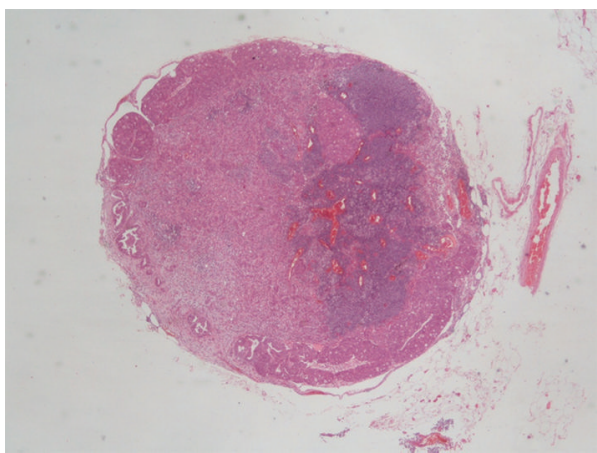

(a)

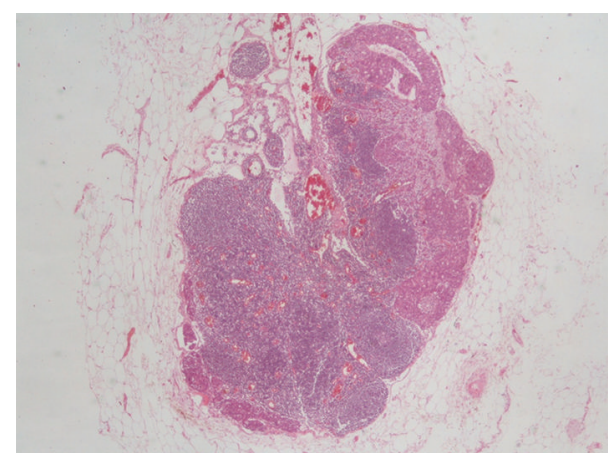

(b)

FIGURE 1: Small metastatic lymph nodes (haematoxylin and eosin stain, $\times 20$ ).

Bjelovic et al. started that within the group of small lymph nodes, $17 \%$ were malignant. Additionally, of all the malignant lymph nodes, $46 \%$ were less than $5 \mathrm{~mm}$ in diameter. Small lymph nodes are commonly nonpalpable. Size and consistency of lymph nodes are not dependable parameters for appraisal of lymph node involvement in tumor tissue [4].

Regarding the other tumoral locations in the body, no clear correlation of lymph node size and metastatic involvement is seen. For example, Vogel et al. measured the diameter of hilar and mediastinal lymph nodes in bronchial cancer. They found no sufficient correlation between the diameter of the lymph node and their infiltration by cancer cells [5].

Prenzel et al. noted that preoperative lymph node staging of lung cancer by computerized tomography relied on the premise that malignant lymph nodes were larger than benign ones. Frequency of metastatic involvement was calculated and correlated with lymph node size. The conclusion was that lymph node size was not a reliable parameter for the evaluation of metastatic involvement in patients with nonsmall cell lung cancer [6].

Macdonald et al. explored the level VI node size as a predictor of malignancy in papillary thyroid cancer. They concluded that the decision to perform a level VI neck dissection could not be based on a preoperative ultrasound size [7].

On the other hand, lymph nodes measuring larger than or equal to $4 \mathrm{~mm}$, especially those located anterior to the midportion of the aorta, should raise a suspicion of metastases in patients with clinical stage I testicular nonseminomatous germ cell cancer [8].

In summary, we can see that the results of different studies are contradictory, because there is no clear correlation between nodal size and the likelihood of the metastasis in lymph node. In our case, the correlation is definitely negative. Although preoperative clinical lymph node staging relies on the supposition that malignant lymph nodes are larger than benign ones, the metastatic status of the small lymph nodes must receive special attention not only by clinicians, but also by pathologists who should aim to recover as many lymph nodes as possible.

\section{Take Home Messages}

(i) For clinicians: small lymph nodes can be metastatic, and large ones can be reactive.

(ii) For pathologists: small lymph nodes should not be neglected and must be picked up and examined thoroughly.

\section{Conflict of Interests}

The authors have declared that no conflict of interests exists.

\section{Acknowledgment}

The patient was followed and treated at Ashkelon Public Medical Centre in Israel.

\section{References}

[1] G. Cserni, "The influence of nodal size on the staging of colorectal carcinomas," Journal of Clinical Pathology, vol. 55, no. 5, pp. 386-390, 2002.

[2] H. Kotanagi, T. Fukuoka, Y. Shibata et al., “The size of regional lymph nodes does not correlate with the presence or absence of metastasis in lymph nodes in rectal cancer," Journal of Surgical Oncology, vol. 54, no. 4, pp. 252-254, 1993.

[3] S. P. Mönig, S. E. Baldus, and T. K. Zirbes, "Lymph node size and metastatic infiltration in colon cancer," Annals of Surgical Oncology, vol. 6, pp. 579-581, 1999.

[4] M. Bjelovic, V. Kalezic, M. Petrovic et al., "Correlation of macroscopic and histological characteristics in the regional lymph nodes of patients with rectal and sigmoidal adenocarcinoma," Hepato-Gastroenterology, vol. 45, no. 20, pp. 433-438, 1998.

[5] P. Vogel, H. Daschner, J. Lenz, and R. Schafer, "Correlation of lymph node size and their infiltration by metastases in lung cancer," Langenbecks Archiv für Chirurgie, vol. 375, no. 3, pp. 141144, 1990.

[6] K. L. Prenzel, S. P. Mönig, J. M. Sinning et al., "Lymph node size and metastatic infiltration in non-small cell lung cancer," Chest, vol. 123, no. 2, pp. 463-467, 2003.

[7] K. I. Macdonald, S. Mark Taylor, J. Cavanagh, J. R. B. Trites, M. J. Bullock, and R. D. Hart, "Level VI node size as a predictor of 
malignancy in papillary thyroid cancer," Journal of Otolaryngology, Head and Neck Surgery, vol. 39, no. 2, pp. 136-141, 2010.

[8] S. Hilton, H. W. Herr, J. B. Teitcher, C. B. Begg, and R. A. Castellino, "CT detection of retroperitoneal lymph node metastases in patients with clinical stage 1 testicular nonseminomatous germ cell cancer: assessment of size and distribution criteria," American Journal of Roentgenology, vol. 169, no. 2, pp. 521-525, 1997. 


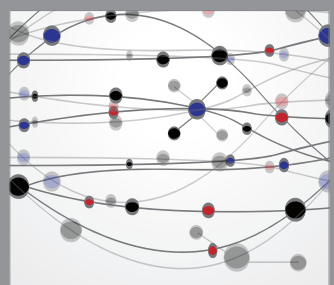

The Scientific World Journal
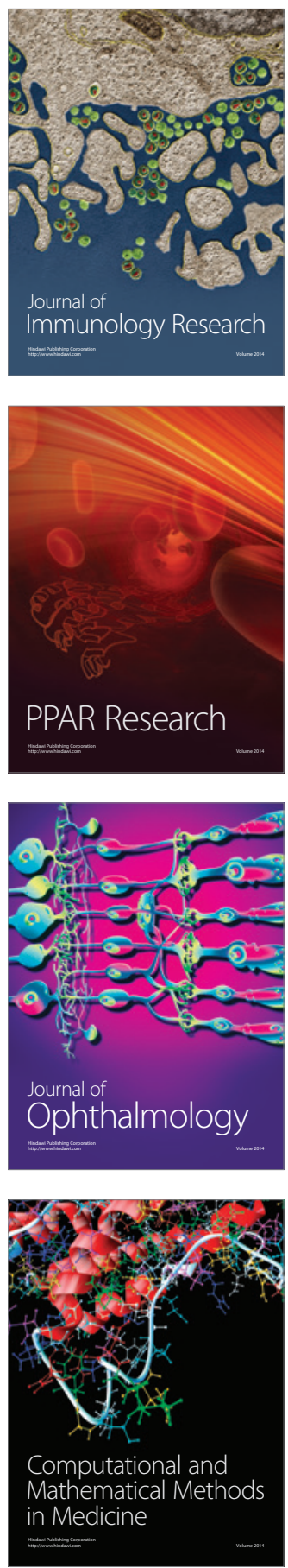

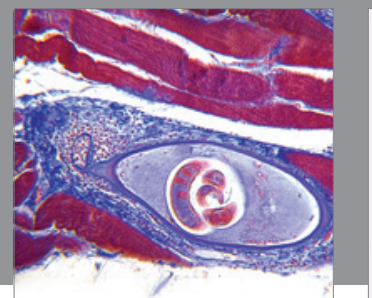

Gastroenterology

Research and Practice
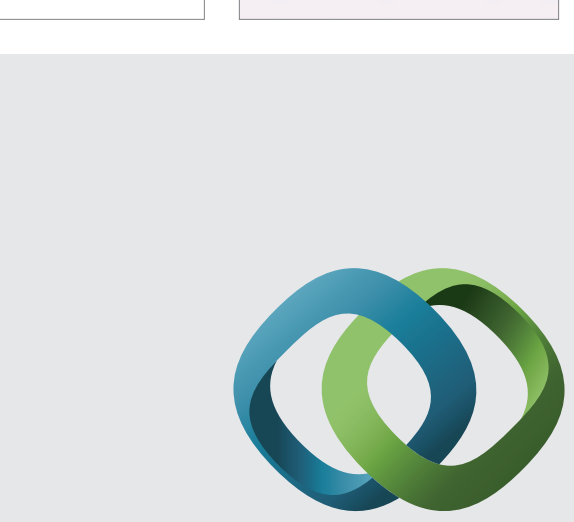

\section{Hindawi}

Submit your manuscripts at

http://www.hindawi.com
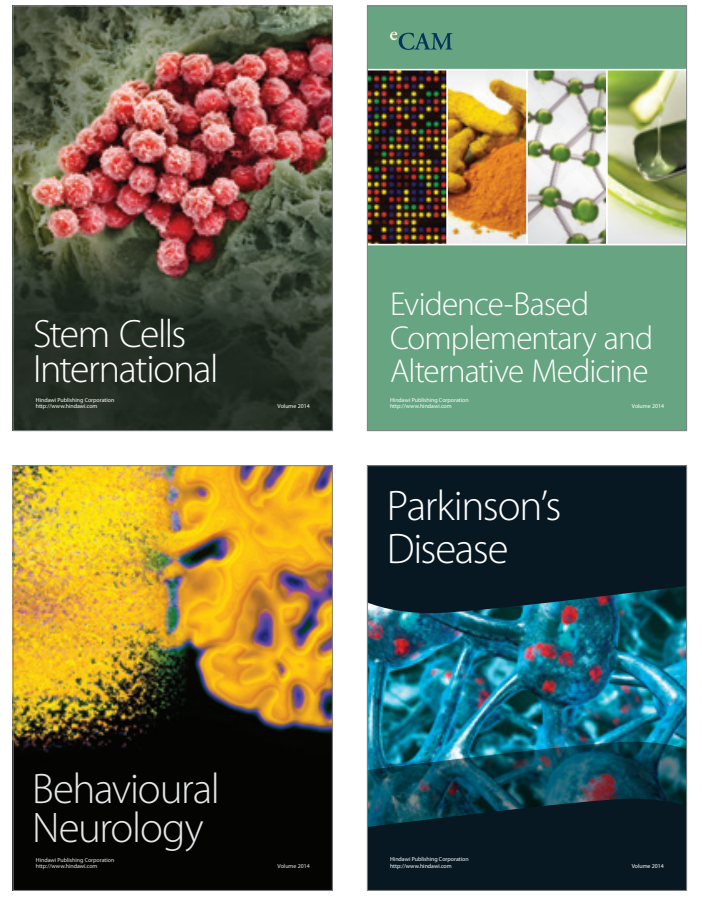
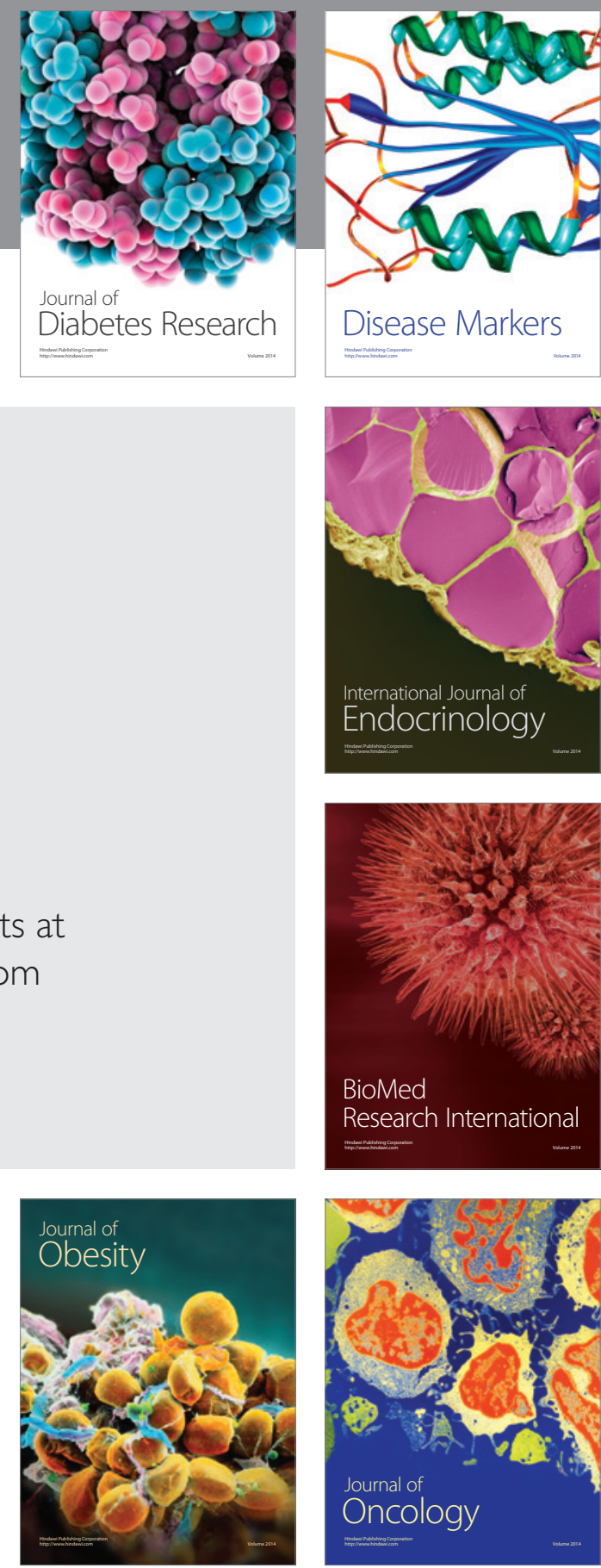

Disease Markers
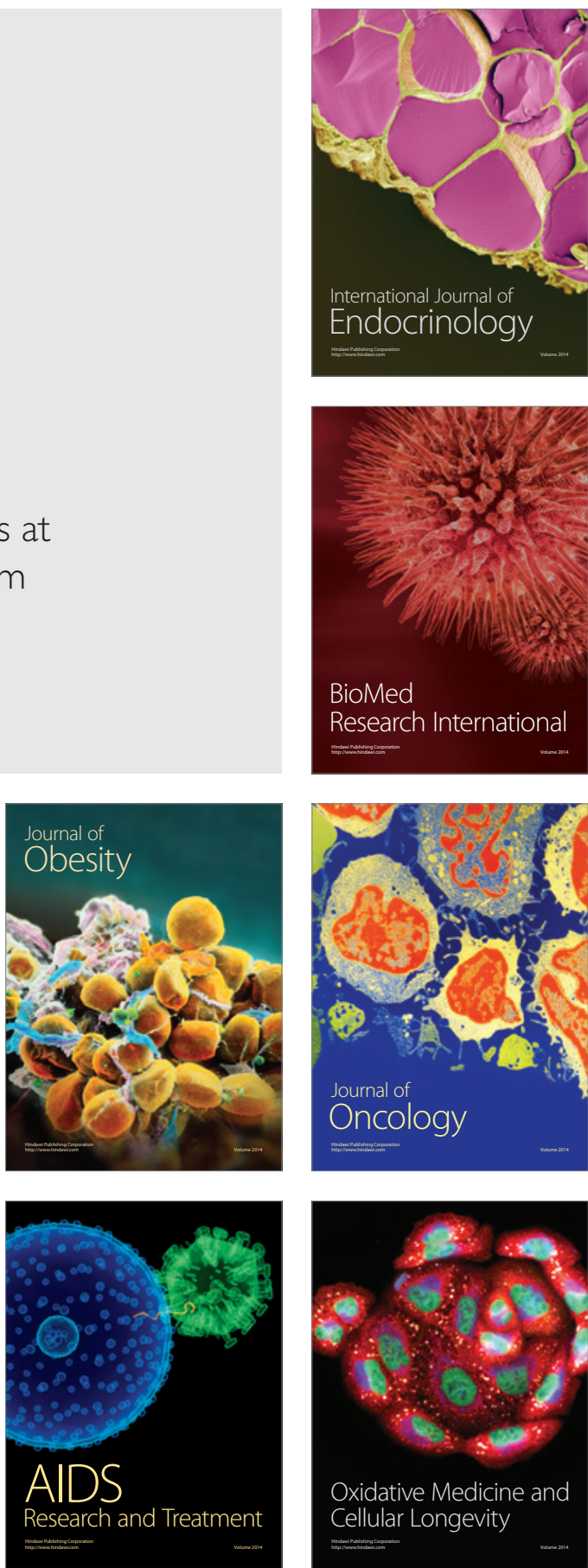